\title{
Web apps characterization, a first step for usability evaluation
}

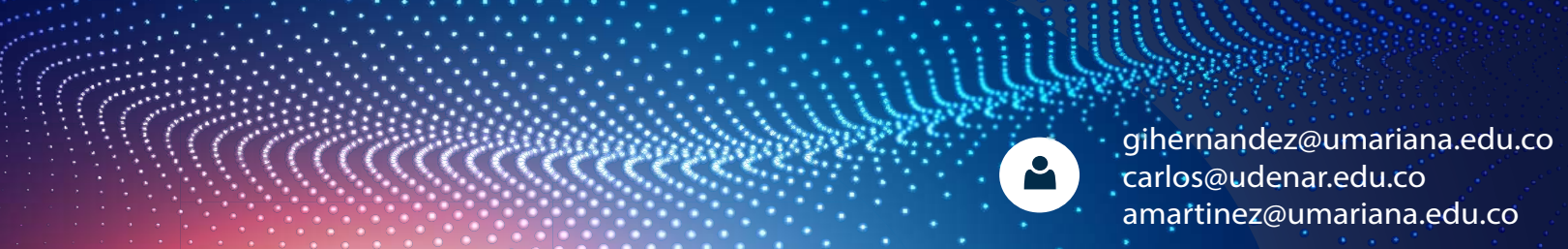
Giovanni Albeiro Hernández Pantoja, Carlos Hernan Guadir Aza, Alvaro Alexander Martínez Navarro
University of Nariño, Mariana University
Pasto - Colombia

gihernandez@umariana.edu.co,carlos@udenar.edu.co,amartinez@umariana.edu.co

\begin{abstract}
About the authors
Author 1: Systems Engineer, postgraduate degree in Computer Management and Master in University Teaching. Full-time professor at the Mariana University (Pasto, Nariño, Colombia). Associate Researcher (Colciencias).

Author 2: Systems Engineer. University of Nariño (Pasto, Nariño, Colombia). SERATIC Development engineer.
\end{abstract}

Author 3: Systems Engineer, Master in University Teaching, Master in Analysis and Massive Visualization of Data. Full-time professor at the Mariana University (Pasto, Nariño, Colombia). Associate Researcher (Colciencias).

\section{ABSTRACT}

The main goal from this article is characterize the web apps developed as grade works, in Systems Engineering's program of Nariño University; as a first step for usability evaluation. This effort was carried out under empiric-analytic approach, of descriptive type. The object population of the study was the web apps developed as a grade works in Systems Engineer-ing's program of Nariño University the years between 2010 and 2017. As a result, web apps were characterized, bearing in mind the variables: quantity, technology, economic sector, de-velopment time, involve and current state. Was identified 71 grade works that developed web apps, where PHP is the back-end language used and a high level does not identify the use of front-end frameworks. In intermedium level, the web apps were developed by one student only. In a high level the web apps were to public entities, being the sectors: education, government and service; the most bounties. The work enables us to conclude that the lowest use of web apps, obey to the relation between software architecture and usability. The intermediate use of back-end web frameworks and the low level of use of front-end frameworks, is a factor that decreases the flexibility to implement usability architectonic tactics a web app. Moreover, teamwork has to be encouraged and propitiate, when software is build.

Keywords: Usability, Usability Evaluation, Web Applications, Web Usability. 


\section{Introduction}

Software usability is a study field from Human-Computer Interaction discipline and is considered as a non-functional attribute that requires a process and engineering to handle it systematically through replicable and flexible methods (Taylor and Francis Group, 2014); its purpose is the user-centered design, which is the basis for a successful interaction process. The content is the primary reason for interacting with a software product.

At the Systems Engineering's program of the University of Nariño, the requirement for the undergraduate degree is performing a deepening project by students. Additionally, this work allows integration and theoretical or theoretical-practical application of knowledge, skills and attitudes; to contribute to the analysis and solution of a problem related to the object of study or an area of the profession (Ordoñez, Hernández Pantoja, Ordoñez, Ordoñez, \& Cobos, 2016) (Ordoñez, Ordoñez, Ordoñez, Cobos, \& Hernández, 2017). Between 2010 and 2017, 30\% of the degree works done by the students were development of web applications. This behavior, although it is not stable, is almost always superior to another type of degree works, because trend of use of web applications is increasing, as well as devices connected to the Internet (ICT Ministry, 2016) (Burak Tekin and Tufekci, 2013).

On the other hand, software development requires quality standards like usability attribute. This is defined as a non-functional attribute of a product or software system; specific users can use it to achieve efficiency and relative satisfaction in a specific context of use (ISO 25000 Standards, 2018). However, a document inspection for web development works revealed that, 93\% of them didn't explicitly identify usability as a non-functional requirement.

Not including usability at the time of software implementation implies that this attribute of quality is not consciously assumed. In addition, by doing an inspection of the curricula, it was possible to identify ten elective subjects, which students can take during the training process. However, none of them focuses on developing skills in building software in a usable way.

Making an inspection of degree works between 2010 and 2017, it was identified that web applications developed were projects for public and private sectors. In this ways, 
the responsibility for software quality in terms of usability becomes a highly desirable attribute; otherwise, as Sanchez (2011) states, web applications poorly usable are definitely abandoned by users since the complexity of use does not allow them to concentrate on activities.

According to the number of web applications developed in degree works and tendencies for using this type of systems, it can be inferred that the percentages will be maintained with a high probability of increasing them. In addition, web applications face a diversity of clients with limitations that require improvements in the content architecture (Lund and Sieverthson, 2017).

The characterization takes different meanings. Nevertheless, the Royal Spanish Academy (2018), defines it as the result of determining the peculiar attributes of something, so that it clearly distinguishes itself from the others. In this way, it is understood as the result of establishing which are the properties that an object has, in relation to a set of variables or indicators, that allow identifying distinctive features as an input to describe an initial state.

Usability has been defined as an attribute of a software product, this can be learned, understood, used and it may be attractive to the user, when it is used in certain contexts (ISO 25000 Standards, 2018). Also, it is understood as a quality attribute that measures the easy-to-use of user interfaces (Jakob, 2012). It is a feature that a software product has to be understood, used, and allows a user to develop a task in a simple way, when used under specific conditions.

Usability evaluation means to apply methods that identify and measure usability problems, and then suggest practical solutions that specify how they could be improved. The methods to evaluate usability have two approaches: subjective and objective. Each approach attempts to measure the interactive user experience (UX) associated with the interface. The usability analysis provides an understanding of UX that helps determine where and how to redesign the interface $(\mathrm{UI})$ to improve the level of interaction and satisfaction (Nagpal, Mehrotra, and Kumar Bhatia, 2017).

The subjective approach according to Fernandez, Insfran, and Abrahão, (2011) and Ndako, Shehi, Adelowo, and Gbenga (2017) divides into three types. Inspection, involving experts evaluating user interface based on design principles and guidelines, group tours or inquiry, a technique carried out by stakeholders of the product simulating common activities in prototypes of the web application, and the third type are user tests, selecting prospects from potential users, to execute specific activities in the software product.

For the previously described, this research was born, which aimed to characterize the web applications developed as degree works, as a first step of the evaluation of subjective usability, in the Systems Engineering program of the University of Nariño.

\section{Materials and methods}

The research that supports this article was made under the quantitative paradigm, with an empirical-analytical approach of a descriptive type. The studied population were the web applications developed as degree works in the Systems Engineering program of the University of Nariño (Colombia) during the years 2010 to 2017. No sampling was done, it was used the total of web applications developed as degree work during the period from 
2010 to 2017 . The technique used to collect the information was the documentary review, where a matrix of characteristics and properties was built as an instrument. For the analysis of the information, descriptive statistics was used as a technique, making a frequency analysis. The variables analyzed were: quantity, technology, economic sector, development time, people involved, and current status.

The quantity variable corresponds to the number of web applications developed in the inspected period, between the years 2010 and 2017. In the technology variable, the backend and front-end of the web applications are analyzed, in order to know the programming or markup languages; and frameworks used for development. The database management system (SGDB) for each one was also identified, making groups for registered trademarks. In the same way, the Internet servers used to deploy the applications. The economic sector variable has to be with the type of company the web application is developed. The categories defined were public, private or mixed companies. The variable time of development, allows knowing the period required for planning, organization and execution of the degree work. The variable people involved, explores the effort required for the development of the degree work, that is, number of students needed for development. Finally, the current state variable describes web applications in production, that is, installed applications that continue working in the organizations for which they were developed.

The work had 2 stages. In the first one, a list of the degree projects developed between 2010 and 2017 was requested to the Systems Engineering department's direction. Subsequently, a classification of the degree works was made, according to the categories: web applications, desktop applications, applications for mobile devices, Software Engineering, auditing, objects or virtual learning environments, networks and telematics; for those jobs that did not match the previous categories, were included in the "other" category. After that, a report was requested to the director of univerty's library. This final report included degree works categorized as web applications. At Systems engineering's direction, the access to repository and to download the source code was asked. Once the documents and resources were obtained, a documentary review sheet was developed using the Objective-QuestionMetric (GOM) technique, based on the defined variables and validated through expert judgment technique. Afterwards, developed web applications were installed and with the final reports of the degree works, the information was compiled, completing a documentary review file for each degree work. Next, a matrix of characteristics and properties was elaborated with the data collected from the documentary review.

On the second stage, it was performed an analysis of data collected through descriptive statistics as a technique, using frequency analysis and constructing categories for the values obtained by each variable and calculating the occurrence of these, through relative and absolute frequencies. These frequencies were moved to frequency tables. Values obtained from the frequency tables were represented by graphs. Finally, on the interpretation of the results, it was described general properties and characteristics of web applications developed as degree work.

\section{Results}

On the first stage of the investigation, general properties of the degree works made between 2010 and 2017 are described. 


\subsection{Description of thesis research studies}

The highest percentage of thesis research studies is oriented to the development of web applications with a 33\%, as can be seen in Fig. 1. They are oriented to software development, because $58 \%$ of them developed some kind of software like web applications, desktop applications, mobile applications, video games or applications for other platforms.

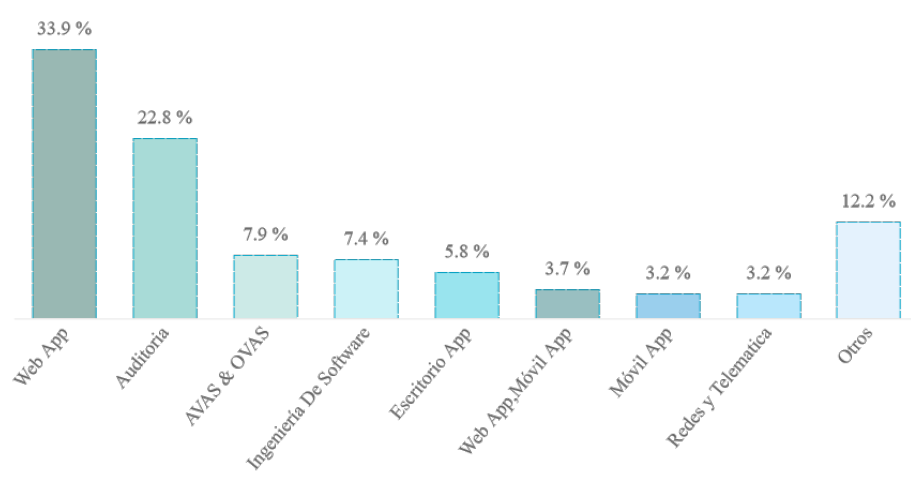

Fig. 1. Types of jobs from grade 2010 to 2017

Fig. 2 shows frequency lines per year for web applications, audits and mobile applications. Audit works have a growth until 2016, between the years 2012 to 2013 they grew by $300 \%$, between the years 2014 to 2016 grew by 225\%. Mobile applications developed as degree works show increasing trends, when comparing between 2012 and 2016 a growth curve is evident.

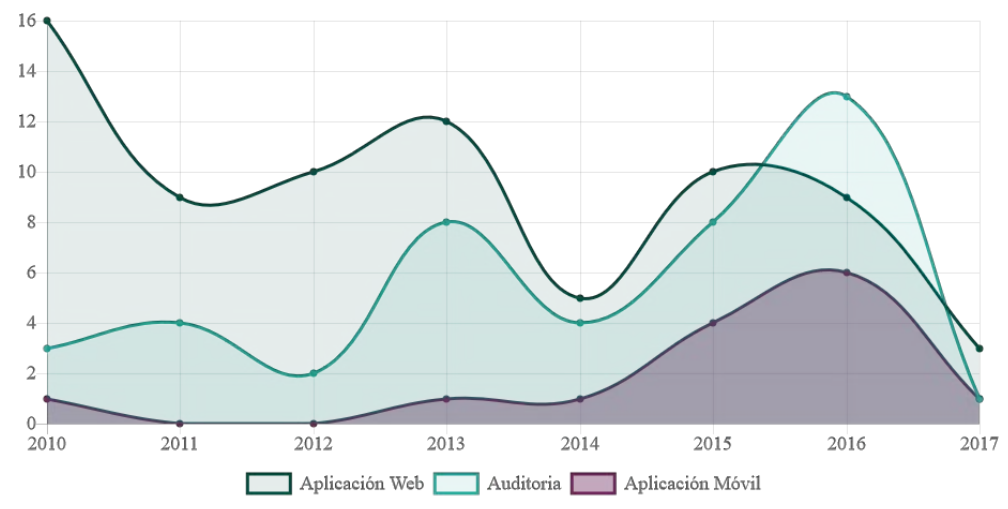

Fig. 2. Web, mobile applications and audits 2010 to 2017

\subsection{Characteristics of web applications}

The characteristics and properties of web applications developed as thesis research studies were analyzed through the variables: quantity, technology, economic sector, development time, people involved, and status.

The characterization made it possible to identify that web applications are a common product of a thesis research study. Fig. 2 shows the frequencies of web applications per year, with a total of 71 applications developed. Between 2010 and 2011 web applications decreased by $43 \%$, the years 2013 to 2014 had a decrease of 58\%. Between the years 2011 to 2013 there is a growth of 25\%, and then between 2014 and 2015 they grow 50\%. 
When developing a software product, tools or technologies are used to implement the functionalities and designs. Web applications require three parts, data layer, business layer (back-end) and presentation layer (front-end).

The logic of the business in a web application, are functions that perform data entry, queries, generation of reports and the required processing, developed under a programming language. As can be seen in Fig. 3, the most used programming languages for the backend construction were PHP with $49 \%$, followed by C \# with $25 \%$.

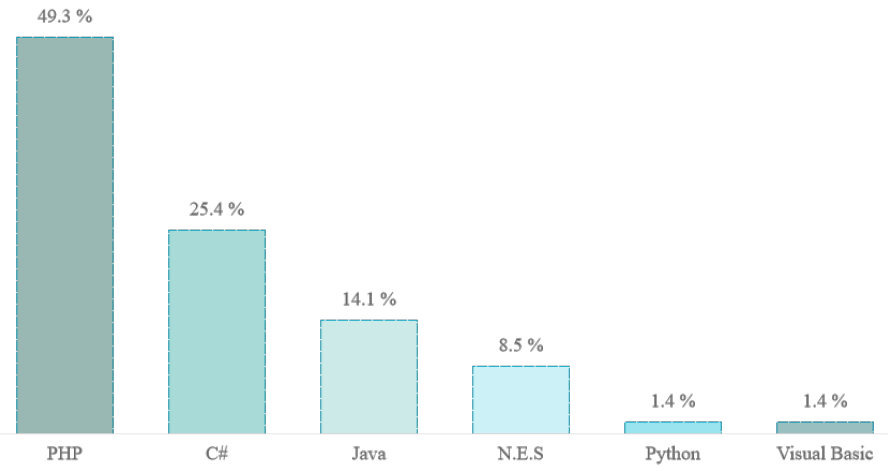

Fig. 3. Back-end programming language

On the other hand, $49.3 \%$ of the works did not specify the use of a web framework, followed by. $\mathrm{NET}^{1}$ with $31 \%$. Another representative group are Java frameworks ${ }^{2}$ with total of $11 \%$.

In relation to the front-end languages, it was identified that the most used were $\mathrm{HTML}$ (74\%), JavaScript (56\%), XML (40\%) and CSS style sheets (32\%). However, 18\% did not specify the use of any of the languages.

The most used front-end frameworks were JQuery (12\%), a JavaScript library used to implement the AJAX technique and manipulate the DOM dynamically. The documentation explained that these techniques were used with the purpose of improving the usability of the application to be built. Other frameworks used are Bootstrap (5\%), JQuery UI (4\%), Metro UI (2\%) and Prime Faces (2\%). In addition, $62 \%$ of the degree papers did not document the use of a front-end framework.

The essence of a web application is the access to data in an interactive way, the data is stored, consulted and updated in the Database Management System (DBMS), part of the data layer. In relation to the technologies for DBMS, it was found that $20 \%$ of the works used licensed software, such as Oracle ${ }^{3}$, Microsoft Access ${ }^{4}$, and SQL Server ${ }^{4}$. As free DBMS, PostgreSQL and MySQL were found, with 36\% and 32\% respectively. In addition, $9 \%$ did not specify the DBMS used.

For implementation of a web application, an Internet server is required. Apache servers ${ }^{5}$ are the most used with $45 \%$. Internet Information Services (IIS) ${ }^{4}$ was used by $22 \%$. This last

1 It is a registered mark of Microsoft Corporation

2 It is a registered mark of Oracle Corporation

3 Oracle: It is a registered mark of Oracle Corporation.

4 SQL Server: It is a registered mark of Microsoft Corporation

5 Apache: It is a registered mark of Apache Software Foundation 
proprietary software was used in the majority of web applications developed under the .NET framework. A find of this research is that $31 \%$ of graduate works did not document the application server used.

For the economic sector variable, it was possible to investigate the types of companies benefited from the development and implementation of web applications. Public entities have the greatest benefit, with $67 \%$. Part of these works were developed for educational centers such as schools or public service companies. According to (Virtual Business Center, 2016) in Colombia, the economic sectors are grouped by the service they perform or they are grouped by the product they commercialize. According to this, it was identified that the sector of the primary economy, was benefited with $2 \%$, in the activity of Agriculture. The works destined to the secondary sector were of $4 \%$ in the Industry activity, and the remaining $94 \%$ belong to the third sector in the activities of education, services, government and others.

The sector with more degree projects related to web applications is education, benefiting universities and schools. The government sector is represented by government entities such as Municipalities, and the Health sector in hospitals. Tourism, transport, and solidarity sectors are grouped between $1 \%$ and $2 \%$. Fig. 4 shows the summary of frequencies of the economic sectors.

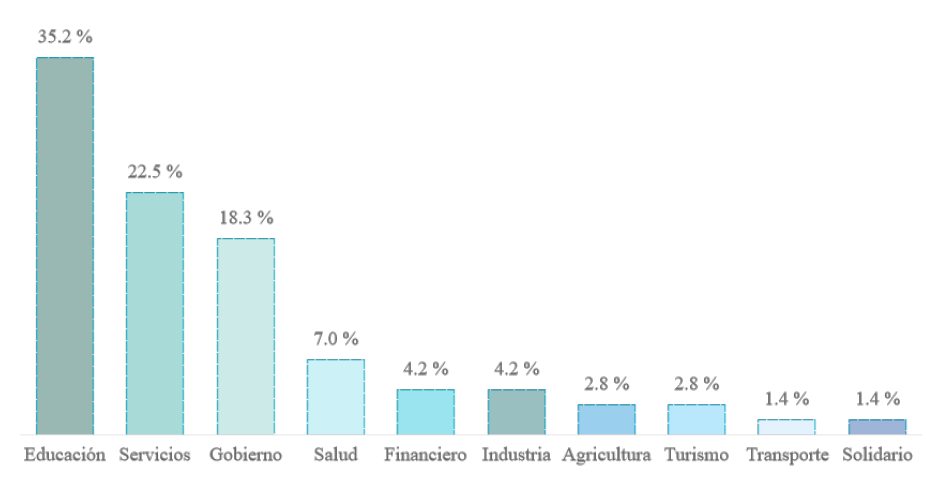

Fig. 4. Economic Sectors

An observation of the final report of degree works, it was evidenced that in $85 \%$, it is not possible to identify the time required for degree work development. The $15 \%$ left described a period between 4 and 16 months, with 6 months being the most frequent period with $7 \%$.

For the number of students responsible for degree work, it was found that 59\% were developed by a single student. According to Noll, Abdur Razzak, Bass, and Beecham (2017), the methodologies suggest a minimum of three people to fill roles and only $2 \%$ meet that requirement. Table 1 shows a summary of people involved in the degree project grouped by gender. In this table, it is observed that women prefer to perform degree work by group. On the contrary, men are the ones who most developed their project individually, with $37 \%$ of the total of individuals. In total $80 \%$ of people involved in web application development are men and $20 \%$ are women. Number of professionals who graduated in a degree project related to the web application development was 107 students. 
Table 1. People Involved at degree work

\begin{tabular}{|c|c|c|c|c|c|}
\hline \multirow{2}{*}{$\begin{array}{l}\text { Number } \\
\text { Involved }\end{array}$} & \multicolumn{2}{|c|}{ Male } & \multicolumn{2}{|c|}{ Female } & \multirow{2}{*}{ Total } \\
\hline & FO & $\%$ FO & FO & $\%$ FO & \\
\hline 1 & 40 & $93 \%$ & 3 & $7 \%$ & 43 \\
\hline 2 & 42 & $72 \%$ & 16 & $28 \%$ & 58 \\
\hline 3 & 4 & $66 \%$ & 2 & $34 \%$ & 6 \\
\hline Totals & 86 & $80 \%$ & 21 & $20 \%$ & 107 \\
\hline
\end{tabular}

An examination of the use of web applications in entities for which they were developed found that $8 \%$ are in operation.

\subsection{Discussion of results}

A recent study on usability by Maat, Swaid, Krishnan, Ghoshal, and Ramakrishnan (2018), proposed a framework for evaluating usability in software products focused on analysis and visualization of scientific data. The framework described is an expansion of Nielsen's heuristics, adapting additional criteria that capture dimensions of usability in the specific type of software. Although Maat, and others (2018), evaluates software products using subjective techniques such as Nielsen's heuristics, in this research, characterization is considered as a preliminary step to subjective evaluation focusing on a type of software such as Web applications.

In the investigation by Elberkawi, El-Firjani, Maatuk, and Aljawarneh (2016), the usability is evaluated in a web-based transactional system for an airline; the applied technique was usability tests with users. As reported by the study, the results were satisfactory, allowing to identify weaknesses and spaces in the system that require recommended solutions for them.

On the other hand, Grigera, Alejandra, Rivera, and Rossi (2016), propose to evaluate the usability with an automatic procedure in web applications in production, the adopted method was usability tests with users, arguing that the information collected belongs to real data of use and experiences of users. The research is similar to this project, because it evaluates usability in web applications. However, it differs in the applied technique. A very important aspect of the research is the use of heuristics for the automatic analysis of user interactions. Other conclusion is that the approach used has some limitations, since there are usability problems that require human reasoning; which becomes as a reference, to include a previous sight of the evaluator through the results of the characterization of web applications.

The work by Jimenez, Lozada, and Rosas (2016), proposed to justify the need to formalize a process for specific development in usability heuristics; and the documentary inspection of 65 articles related to the technique was done. In summary, Nielsen's heuristics were the basis for most of the studies on usability evaluation; and it was possible to demonstrate that there are no previous actions that provide information to apply a subjective technique.

In the study conducted by Paz, Villanueva, and Pow Sang (2015) a web application was evaluated through heuristics and usability test with end users, the intention was to determine a method to find the maximum percentage of usability problems. The researchers manage to conclude that with respect to usability tests with the user, the heuristic evaluation covers 
$90 \%$ of the usability problems found. The similarity with this project is the evaluation of the usability of web applications. However, they focus on evaluating a web application and they do not take into account any previous step to perform the usability evaluation.

Previous investigations described above, show an important investigative path in the evaluation of web usability, some of them using heuristic methods, mainly the one proposed by Nielsen; and usability tests. However, there is a gap in making use of characterization as a preliminary step to the subjective evaluation of web usability.

The characterization of web applications, as a first step to usability evaluation, allows an approach to the software architecture, since it reveals the conditions for software development. According to Martin (2017), the architecture is visualized in the coding, in this case development technologies used are an important part for the implementation of architectural usability strategies, taking into account that some tools are designed to follow certain patterns of development or programming paradigms. The intermediate use of frameworks based on the design pattern Model View-Controller (MVC) could be a factor that decreases the flexibility to implement the tactics and architectures required in usability. Relationship between information architecture and usability is described by Jakob Nielsen (cited by Morville, Rosenfeld, and Arango (2015)) Similarly, the low use of frontend frameworks implies difficulty in implementing usability, according to Katzmaier and Hanneghan (2015) frameworks provide elements based on design patterns, which help to organize the project, and to reuse components. Purpose of this research is not generate a frameworks dependency because architecture is the important fact, however, tools can be configured according to the needs and become constructive factor.

The growth of mobile applications is due to the expansion of smartphones with Android, a Google's operating system. According to Stat Counter (2018), around the world Android has more users than Windows, a desktop operating system. Compared to mobile platforms, Android has $74 \%$ of the market; this could show a trend to develop applications for mobile devices, since the exchange of information on the Web will be given in greater quantity through this type of devices.

On the other hand, the number of people involved allows us to observe that it is necessary to motivate and promote team work in students. When grouping by gender, it was confirmed that $20 \%$ were women who were involved in the development of web applications, this percentage is close to the one reported by Pardo D. (2016), which according to the Ministry of Education of Colombia, the career of Systems Engineering has a percentage of $26 \%$ of women enrolled.

For web applications, a very low percentage of applications in production was found, or available to access from a web client, it is considered as an opportunity for improvement. According to Morville, Rosenfeld, and Arango (2015) there are reasons why a web application is no longer used, difficulty in finding information, lack of interactivity or learning, and difficulty in maintaining or modifying the system. Martin (2017) ensures that maintainability and modifiability not only affects the product, but also developers, causing serious economic losses. For these reasons, it is important to look for strategies that increase the percentage of software products in production, to extend the useful lifetime, after they have been developed as degree works. In the same way, practices that improve the quality of this type of products should be encouraged, since they are used in all economic sectors. For Pressman and Maxim (2015), the semantic web will lead to more and more sophisticated 
web applications, with access to information in an extraordinary way.

\section{Conclusions}

The very low level of use of web applications developed as a thesis research work is due to relationship between software architecture, usability and other quality attributes. Usability is applied through architectural strategies, which are identifiable at a very low level in the documentation of the works.

The intermediate use of back-end frameworks based on the MVC design pattern and the low level of use of front-end frameworks is a factor that decreases the flexibility to implement architectural usability tactics in a web application.

The construction of software is a complex activity that requires the effort of a group of people to give an effective and efficient response to the changing and urgent needs generated by organizations. In an intermediate level, some undergraduate works are developed individually, and, for this reason, teamwork should be promoted and encouraged for software development.

\section{References}

Burak Tekin, F., \& Tufekci, A. (2013). A Case Study for the Usability of Public Institutions: Turkish State Meteorological Service web site. Ankara, Turquia.

Centro Virtual de Negocios. (2016). Cuáles son los sectores económicos de Colombia. Recovery April, 8 2018, from Centro Virtual de Negocios: https://www.cvn.com.co/ cuales-son-los-sectores-economicos-de-colombia/

Elberkawi, EK, El-Firjani, NF-M., Maatuk, AM, \& Aljawarneh, SA (2016). Evaluation of Webbased Systems: A New Method and Results. (IEEE, Recopilador) Agadir, Morocco, Libia, Jordania.

Fernandez, A., Insfran, E., \& Abrahão, S. (17 de Marzo de 2011). Usability evaluation methods for the web: A systematic mapping study. Valencia, España: 2011 Elsevier.

Grigera, J., Alejandra, G., Rivera, JM, \& Rossi, G. (19 de diciembre de 2016). Automatic detection of usability smells in web applications. Int. J. Human-Computer Studies. La Plata, Argentina: (C) 2016 Elsevier.

ISO 25000 Standards. (2018). Usability. (ISO/IEC) Recovery March 8, 2017, from Calidad del Producto Software: http://iso25000.com/index.php/en/iso-25000-standards/iso25010/61-usability

Jakob, N. (2012). Usability 101: Introduction to Usability. (N. Jakob, Editor) Recovery February 8, 2018, from NN/g - Nielsen Norman Group: https://www.nngroup.com/ articles/usability-101-introduction-to-usability/

Jimenez, C., Lozada, P., \& Rosas, P. (2016). Usability Heuristics: A Systematic Review. IEEE. Quito, Chimborazo, Ecuador: IEEE Explore. 
Katzmaier, A., \& Hanneghan, M. (2015). Design Pattern Evaluation of Mobile and Web Based Application Frameworks. Developments in eSystems Engineering (DeSE). (I. Explore, Recopilador) Abu Dhabi, United Arab Emirates.

Lund, M., \& Sieverthson, H. (2017). Usability Challenges For The Mobile Web An Enterprise Perspective. Information Systems. Boras, Suecia. Recovery August 20, 2017, from http://www.diva-portal.org/smash/get/diva2:1088297/FULLTEXT01.pdf

Maat, M., Swaid, S., Krishnan, H., Ghoshal, D., \& Ramakrishnan, L. (2018). Usability Heuristic Evaluation of Scientific Data Analysis and Visualization Tools. Advances in Intelligent Systems and Computing. Berkley, California, USA: Advances in Usability and User Experience.

Martin, R. (2017). Clean Architecture: A Craftsman's Guide to Software Structure and Design (First Edition ed.). USA: Prentice Hall.

Ministerio TIC. (2016). El Gobierno Digital y Las Tendencias Mundiales. 17. (I. Mejia, Ed.) Bogota. Recovery Febraury 18, 2017, from http://www.mintic.gov.co/portal/604/ articles-15256_recurso_1.pdf

Morville, P., Rosenfeld, L., \& Arango, J. (2015). Information Architecture for the World Wide Web - Designin for the Web and Beyond (Fourth Edition ed.). Sebastopol, California, Estados Unidos: O’Reilly Media, Inc.

Nagpal, R., Mehrotra, D., \& Kumar Bhatia, P. (2017). The State of Art in Website Usability Evaluation Methods. Uttar Pradesh, India: British Cataloguing in Publication Data.

Ndako, VA, Shehi, IS, Adelowo, SA, \& Gbenga, RJ (14 de Mayo de 2017). Towards Designing Mobile Banking User Interfaces for Novice Users. (@. S. 2017, Recopilador) Minna, Nigeria.

Noll, J., Abdur Razzak, M., Bass, J., \& Beecham, S. (2017). A Study of the Scrum Master's Role.

Ordoñez, C., Hernández Pantoja, G. A., Ordoñez, H., Ordoñez, A., \& Cobos, C. (2016). Virtual Community of Practice to potentiate knowledge and skills for building mobile applications in computer science students. En 8th Euro American Conference on Telematics and Information Systems (EATIS). Cartagena de Indias - Colombia: IEEE.

Ordoñez, C., Ordoñez, H., Ordoñez, A., Cobos, C., \& Hernández, G. (2017). Strengthening Competencies for Building Software, Through a Community of Practice. Advances in Computing. CCC 2017. Communications in Computer and Information Science, vol 735., 415-426.

Pardo D., J. (2016). Se Buscan Ingenieras. (E. Tiempo, Ed.) Recovery April 10, 2018, from El Tiempo: http://www.eltiempo.com/carrusel/las-mujeres-en-la-ingenieria-encolombia-38494

Paz, F., Villanueva, D., \& Pow Sang, JA (2015). Heuristic Evaluation as a Complement to Usability Testing - A Case Study in Web Domain. 2015 12th International Conference on Information Technology - New Generations. Lima, Peru: IEEE.

Pressman, R., \& Maxim, B. (2015). Software Engineering - A Practitioner's Approach (Eighth 
Edition ed.). New York, New York, USA: McGraw-Hill Education.

Sanchez, W. (2011). La usabilidad en Ingeniería de Software: definición y características. Recovery September 18, 2016, from Redicces Org:http://www.redicces.org.sv/jspui/ bitstream/10972/1937/1/2.\%20La\%20usabilidad\%20en\%20lngenieria\%20de\%20 Software-\%20definicion\%20y\%20caracteristicas.pdf

Stat Counter. (2018). Operating System Market Share Colombia. Recovery April 9, 2018, from Global Stats: http://gs.statcounter.com/os-market-share/all/colombia/

Taylor \& Francis Group. (2014). Computing Handbook - Information Systems and Information Technology (Thirth Edition ed.). (H. Topi, \& A. Tucker, Edits.) Waltham, Massachisetts, USA: CRC Press. 